\title{
What can we learn about South African households by comparing the national Census 20I I with the Agincourt Health and Demographic Surveillance System data in rural northeast Mpumalanga?
}

\author{
Mercy Shoko ${ }^{1,2}$, Mark A. Collinson ${ }^{3,4,5}$, Lesego Lefakane ${ }^{1}$, Kathleen Kahn ${ }^{3,4,5}$ and \\ Stephen M. Tollman ${ }^{3,4,5}$
}

\author{
${ }^{1}$ Statistics South Africa, Pretoria.
}

Mercysh@statssa.gov.za

\author{
${ }^{2}$ School of Public Health, Faculty of Health Sciences, University of the Witwatersrand, Johannesburg \\ ${ }^{3}$ MRC/Wits Rural Public Health and Health Transitions Research Unit (Agincourt), School of Public \\ Health, Faculty of Health Sciences, University of the Witwatersrand, Johannesburg. \\ ${ }^{4}$ Umeå Centre for Global Health Research, Umeå University, Sweden \\ ${ }^{5}$ INDEPTH Network, Accra, Ghana
}

\begin{abstract}
Households are central to demographic processes; fertility, mortality and migration. In South Africa, households are important socio-economic units that are at the core of service-delivery planning. While the concept of a household in the country is not in dispute across surveys - it is a socio-economic unit based on shared resources and co-residency - household definitions vary by enumeration methodology. Researchers have, however, not taken full advantage of the availability of the multiple data sources for measuring demographic phenomena. Among the sources of household data in the country are health and demographic surveillance systems and the national census, which are used together in this study to examine the population and household dynamics in a rural sub-district of South Africa. Key findings are that there are obvious differences in the population and household estimates between the two data sources, largely explained by the variations in household definition and data collection procedures.
\end{abstract}

Keywords: South Africa; Agincourt; household; census; migration

\section{Introduction}

Households are important socio-economic units that are at the core of service delivery planning, driven by the 1998 South African National Population Policy that places population at the centre of policy and development, and regards people as the driving force and ultimate beneficiaries (Republic of South Africa, 1998). The National Development Plan (NDP) stresses the importance of healthy and resilient households to achieve the country's vision for development (Republic of South Africa, 20II). However, keeping track of the number, size and composition of households has methodological challenges including definition and measurement. Different demographic approaches, ranging from national censuses, to surveys and health and demographic surveillance systems each make important contributions, but studies that draw from more than one type of data system and draw conclusions from their triangulation remain rare.
The objectives of this study are to compare data in the same geographic area from the national census in $20 \mathrm{II}$ and from health and demographic surveillance system records in the corresponding year to gain insight into household dynamics that go further than can be provided by any one dataset. We compare the number of households, average household size, population size as well as age structure from the National Census of 20II and the Agincourt Health and Demographic Surveillance system in rural Mpumalanga Province, also in $201 \mathrm{l}$.

\section{Literature review}

Literature on household analysis in South Africa, and more broadly on the continent, has raised important issues which help to frame the contribution of this paper. Questions have been raised about whether households are valid constructs in large surveys and censuses on the African continent (Rabe, 2008; Ziehl, 200I). In the development of standards for 
comparable methods of conducting modern censuses, the household concept was not universally adopted by African National Statistics Offices until the 1990s (Kiregyera, 2015). However, the value of comparability within and between countries has resulted in the concept of a household now being universally accepted on the continent. In South Africa, a debate occurred in the literature examining whether nuclear families were increasingly the norm in modernising and urbanising societies pointing out that 'Western' households, which tend to be conjugal in nature, should not be automatically aggregated with 'African' households, which tend to be based on consanguinal or kinship-linked processes, because the household composition can mean different things in different contexts (Russel, 2003; Ziehl, 200I; Rabe, 2008). Again, the value of statistical uniformity in producing evidence for policy-making has won out over time and now surveys and censuses in South Africa systematically use a household concept in defining a social unit and structuring data in coresidential units (Kiregyera, 2015; Statistics South Africa, 20I4). Nevertheless, it is recommended that interpretations of quantitative data on households proceed carefully, and, where possible, incorporate insights from qualitative studies and other data sources (Rabe, 2008; Ziehl, 200I).

A difference in household definition that is recognised in demographic methodology is to discriminate between de facto and de jure censuses. A de facto census has a household definition that includes people that are co-resident at a given census reference period. Conversely, a de jure census includes those who are bona-fide household members, whether present or absent at the time of the interview (Van de Walle, 2008). De facto household definitions are the standard approach for national censuses. This definition allows comparability across countries (UN, 1954), and minimise the risk of people being counted in more than one household, which may inadvertently inflate population size. De jure household definitions are used in some health and demographic surveillance systems and national surveys. These enable the production of data on temporary migrants who reside near their work place (Posel and Casale, 2003; Collinson, 2010); and dependent children who are residing at an educational facility. Another value of a de jure household definition is that it provides data on children left behind when mothers migrate for work purposes so that information of the mothers is made available (Bennet, et. al. 20I5; Madhavan, et. al. 20I2).

A recent paper by Wittenberg and colleagues shows trends in household size in South Africa using the series of national censuses, with a de facto definition, and two longitudinal datasets, namely, the nationally representative National Income Dynamics Panel Study and the Agincourt Health and Demographic Surveillance System both with a de jure definition (Leibbrandt, et. al, 2009, Kahn, et. al., 20I2). The results suggest that the average household size is larger for de jure households compared to de facto; and in all three data sources the average household size is declining over time. The mechanism of the average household size reducing is examined in this paper using the data sources that have a temporal dimension, and show that the main demographic driver is a rapid formation of new households that are smaller in size, rather than aggregate changes in large households becoming smaller (Wittenberg, et. al., "Submitted").

Other studies point to the dynamic nature of households. Longitudinal data can be used to show that households are gaining and losing people all the time and that a tabulation of household types in a cross-sectional dataset belies the fact that flux occurs within households (Ziehl, 200I; Wittenberg, et. al., 2007).

Triangulation of different data sources has been used in different ways to cross-validate findings and gain insights from different household definitions, including the examination of household size mentioned above; and migration and urbanisation, taking into account temporary migration (Ginsburg, et. al., In press). Another example is using health and demographic surveillance system (HDSS) mortality data with cause-of-death attribute made through verbal autopsy (Byass, et.al., 20l0; Kahn, et. al., 20I2) to compare and validate national mortality statistics obtained through civil registration (Kabudula, et al., 20।4).

\section{Conceptual framework}

Firstly, geographical alignment is a key concept, using a geographic information system (GIS) to compare data on the same population with complementary methodologies, namely national census and Health and Demographic Surveillance System data. Secondly, triangulation is a key concept aiming to shed light on the interpretation of national census data and household dynamics that are not revealed in the cross-sectional, national census. This comparison benefits from the fact that the two data sources have different household definitions, one with a de facto and one with a de jure household definition.

\section{Data Sources}

Agincourt Health and Demographic Surveillance System (HDSS)

The Agincourt Health and Demographic Surveillance System Site (HDSS) is situated in Bushbuckridge, a 
sub-district of Ehlanzeni District, Mpumalanga province, South Africa. It is located in the rural northeast part of the country close to the Mozambique border. Historically, this was part of the "homeland" of Gazankulu, characterised by poor agricultural land, underdeveloped infrastructure and maintained as labour reservoirs for the apartheid government (Kahn, et al., 20/2). The area has experienced a great deal of circular migration both before and after the fall of apartheid' although with different patterns (Collinson, 2010).

The Agincourt HDSS is a member of the International Network for the Demographic Evaluation of Populations and Their Health (INDEPTH), a network of HDSS Centres found in low and middle income countries. It is one of the three HDSS Centres in the country (the others being the Africa Centre HDSS, KwaZulu-Natal and Dikgale HDSS, Limpopo Province). Agincourt HDSS covers a diverse population with approximately a third being self-settled Mozambican immigrants who were formerly refugees from the Mozambican civil war in the mid-1980's (Dolan et al. 1997; Kahn, et.al., 20I2). The Human Research Ethics Committee (Medical) of the University of the Witwatersrand has reviewed and approved the Agincourt HDSS (M960720 and M08II45).

The Agincourt HDSS program commenced with a baseline census of 21 villages in 1992 and later extended to incorporate six other villages in 2008 to currently covering an area of approximately $420 \mathrm{~km}$ and totalling $3 \mathrm{I}$ villages (www.agincourt.co.za). From 1992 data has been collected longitudinally with an annual update of households' demographic and health data (Tollman, et.al., 1999; Kahn, et.al,. 2012).

\section{Definitions used in the Agincourt HDSS}

Like other South African HDSSs, the Agincourt HDSS has adapted the definition of households to suit the highly mobile population in the area to include local residents and household members present for limited periods called temporary migrants (Kahn, et. al., 2012; Bennett, et.al., 2015). The enumeration methodology is de-jure and the definition of a household is a social group that usually resides and eats together, plus the linked temporary migrants who would eat with them on their return. This definition retains links between temporary migrants and their rural household.

A temporary migrant is a household member who is away the majority of time, but retains a significant link to their base household. A six month per year cut-off was chosen to differentiate 'temporary

\footnotetext{
${ }^{1} 1994$ marks the end of the apartheid era characterised by all-round discriminatory and segregation policies including aspects of the population statistics.
}

migrants' from 'local residents'. Thus, people who are referred to as temporary migrants were absent from the household for more than six months of the year preceding observation, but considered the index household in the HDSS to be their home base. Temporary migration status is based on 'resident months' status which records the amount of time each person is physically present in the household during the year preceding the interview. The fieldworker hears the account of a person's residence pattern and adds together the periods of home residence, rounds this up to a whole number and records it as the number of months that a person was present in the previous year. Based on these 'resident months', the fieldworker updates a 'residence status' variable, which has four categories, namely, 'Local resident', if 'resident months' is between six and twelve months; 'Temporary Migrant', if 'resident months' is less than six and the reason for absence is work-related; 'Other Temporary Migrant' if 'resident months' is less than six and the reason is not workrelated; and 'Visitor' is if a person was present at the time of the interview but should not be considered part of the household.

The residence definition for recording children is to record them at the place where they spend the majority of their time, even if there is another household where a significant other adult stays, such as a separated parent, with which they have contact.

The Agincourt definition of permanent migrant is a person who enters or leaves a household with a permanent intention, whether within or outside the boundaries of the HDSS. The respondent informs the fieldworker that the migration is 'final' (Madhavan, et. al., 2009). An implication of this definition is that when a fieldworker encounters a permanent outmigrant the person is removed from the household list, (whereas a temporary migrant is not), and if they migrated outside the HDSS, they cease to be part of the system but if they left the index household and established a household or joined a household within the HDSS, they lose membership to the previous household and gain membership to a new household.

\section{South African population and housing censuses}

Censuses in South Africa date back to the first census in $191 \mathrm{I}$, and thereafter, numerous other censuses were undertaken with the latest in 20l I. According to Mostert, van Tonder and Hofmeyr (1987:3) cited in (Moultrie and Timaeus, 2002), "the census coverage of the African population in the 1904, 1911 and 1921 censuses is viewed as poor in all respects, the 1936 and 1970 censuses as reasonably good, and those of 1946, 195I, 1960 and 1980 again as less good". Post 1994 censuses conducted in 1996, 2001 and 20II; although with reported limitations of 
coverage and data quality issues; have provided widely available, comprehensive and nationally representative demographic data not available hitherto (Moultrie and Timaeus 2002).

\section{Definitions used in the National Census}

The South African population and housing censuses are de-facto censuses, i.e. people are enumerated in reference to where they were at the census reference period regardless of being usual residents or visitors in the respective households ${ }^{2}$. The assumption for de-facto population is that the population is mobile. The methodology may have limitations for household analysis in South and subSaharan Africa where households can be complex, fluid and geographically dispersed (McDaniel and Zulu, 1996; Young and Ansell, 2003). Additionally, de-facto methodology may be problematic to implement where the census fieldwork extends for a relatively long time, because the fieldworkers have to remember to insist on the reference period which might also present recall problems for respondents.

The household questionnaire was one of the three questionnaire types available for the census and is the one from which the household information for individuals in a household set-up was obtained. The other two questionnaires capture individuals in transit or in institutional settings. The enumeration period was from the $10^{\text {th }}$ to the $31^{\text {st }}$ of October, however due to logistical constraints enumeration was extended for more weeks, but with the midnight of the 9th to the 10th of October as the reference date (Statistics South Africa, 20I2).

\section{Census 20I I weighting methodology}

The census is meant to be a universal coverage of the population, but sometimes the population can be under or over-counted, so a system of weights is employed to obtain an estimate of the country's true population. For Census 201I, the dual system estimation was used to arrive at the true population of the country. This means that two independent sources or 'systems' are used to arrive at the estimate of the true population: the census and Postenumeration survey (PES). The PES is an independent sample survey that is conducted immediately after the completion of census enumeration in order to evaluate the census coverage and content errors. Census and PES estimates contribute to the dual-system estimate of the true population. In the end, the true population is compared with the census-enumerated population

\footnotetext{
${ }^{2}$ Disaggregation by usual residents and visitors can only be done for persons on the household schedule using a six-month cut-off and information from the migration schedule.
}

and the difference is the net undercount (or overcount). From this, weights are developed to adjust the census population to the true population and are available in the dataset. A detailed methodology can be found on the national statistical office responsible for conducting the census, Statistics South Africa (StatsSA) website: http://www.statssa.gov.za.

\section{Triangulating Census and Agincourt HDSS data}

The study uses the Agincourt HDSS data and the corresponding data from the 20ll South African population and housing census data. Several Agincourt HDSS field staff members were involved in the census enumeration in the sub-district, which is good for empowerment of local communities and to ensure community co-operation. However, we are not certain of the extent to which that could have compromised the compliance with census methodology when they had to use a different enumeration methodology.

We applied census weights for census estimates. Variations have been noted in census coverage for sub-national levels and we are not certain of the coverage for Agincourt area, because the percentage undercount was not available at levels lower than the provinces. In the study we therefore present both weighted and unweighted figures.

To compare the geographic areas we used HDSS shapefiles and census shapefiles with specific procedures followed to have comparable data. Agincourt data includes ESRI' shapefiles obtained from the global positioning system (GPS) coordinates obtained by geo-referencing residential units using the GIS. The perimeter and the outline shapefiles from HDSS data show the geographical boundary for the site and for each of the villages. In the census, for logistical and administrative purposes, the country is divided into Enumeration Areas (EAs) which are the smallest geography units. The 201 I census shapefiles at municipal level come from the Municipal Demarcation Board of South Africa whose function of delimiting the country's district, municipality and electoral ward boundaries is provided for in the country's constitution. The Board use the World Geodetic System 1984 coordinate reference system and geographic datum. Statistics South Africa Geography department then further demarcates the shapefiles to lower geography levels. Shapefiles exist at different census geography levels with the lowest being at EA level.

The Agincourt HDSS shapefiles were overlaid on the census shapefiles. We then selected EAs that were intersected by the border of the HDSS perimeter. Overlay of Agincourt shapefiles as well as EAs from census $201 \mathrm{I}$ with the perimeter border of 
Agincourt is shown in Figure I below. The map shows that the overlay of the two data sets was near perfect and therefore reasonably comparable geographically. We then extracted household data for the respective EAs from census data. We assume that Agincourt area typifies the South African rural and former homelands and so examination of the patterns in Agincourt household structure and composition using HDSS data to some extent can be extrapolated to similar areas. Additionally; the corresponding analysis of average household size can be understood in the context of "rural to urban" migration.

Figure I: Agincourt HDSS using shapefiles from $20 \mathrm{II}$ census and HDSS shape files

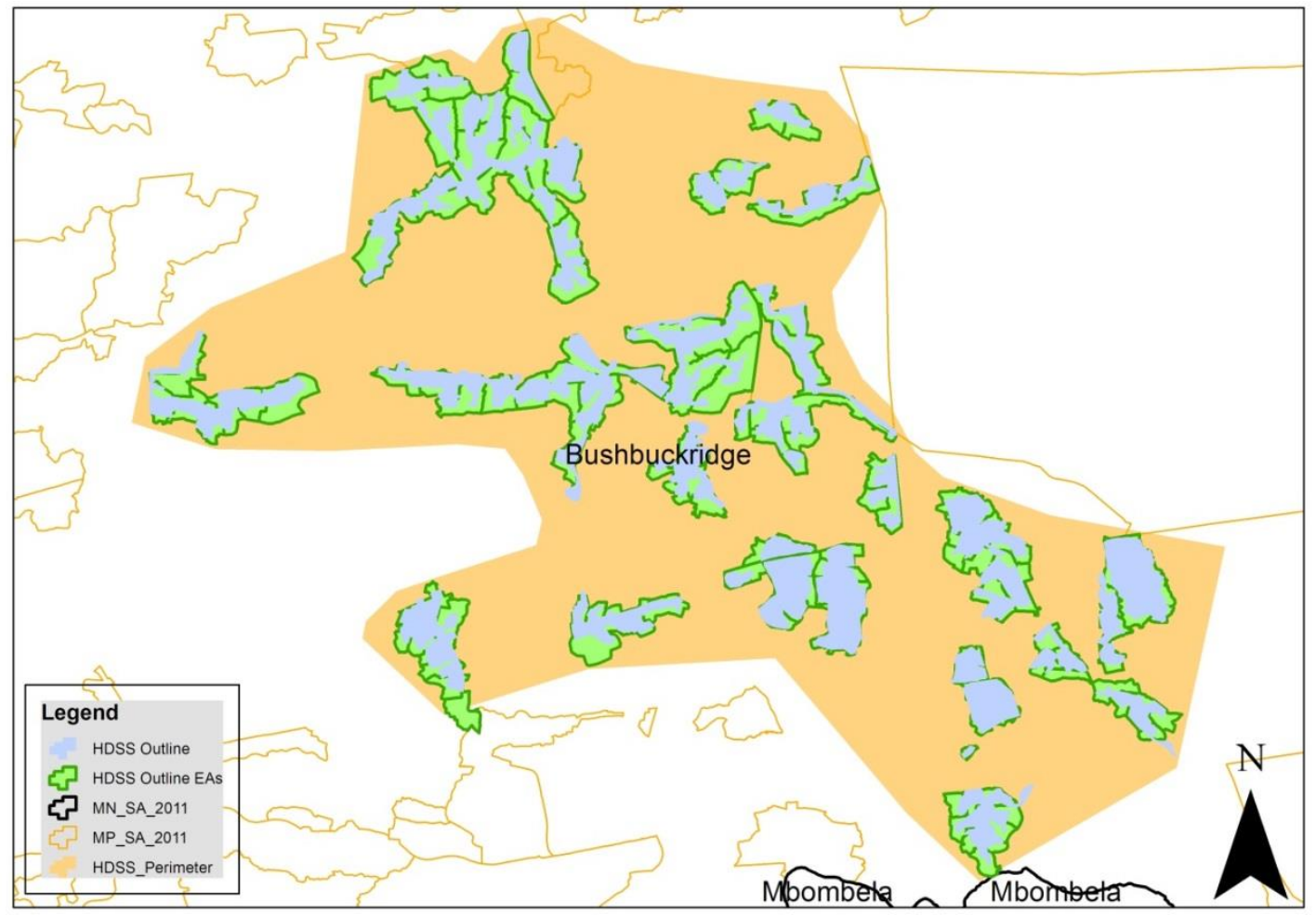

MN stands for Municipality, MP for Mpumalanga, SA for South Africa and $201 \mathrm{I}$ refers to the year version of the boundaries updates

\section{Results}

The results are presented as comparable population indicators in 201 I from the national census and HDSS data from the same geographical area.
Figure 2 shows that the overall population size in the unweighted national census is 84,165 and the weighted number is 94,542 . The HDSS gives the population number at 90,000 persons.

Figure 2: Number of persons by source of data

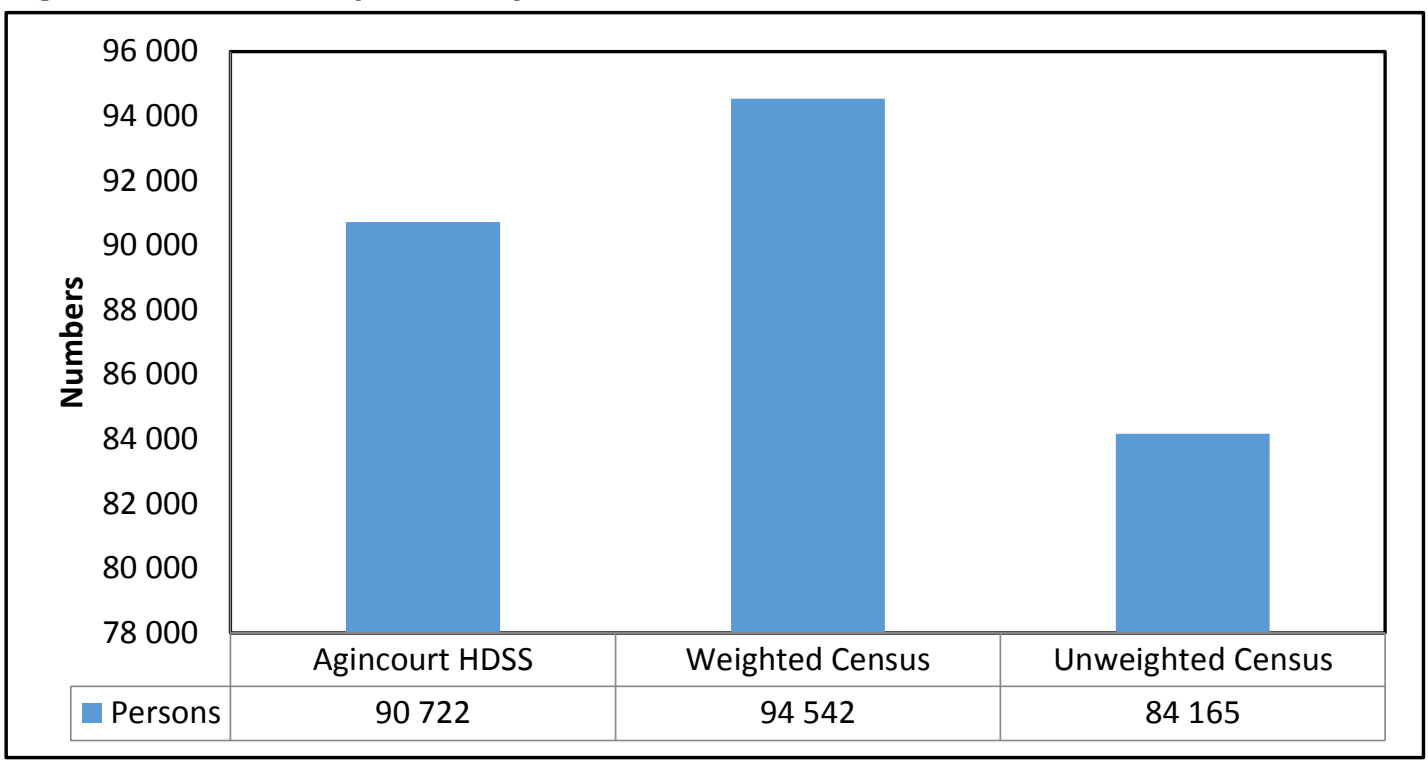

The number of households in the sub-population also differs between the national census and HDSS (Fig 3). 
The national census weighted data shows 23,000 households and unweighted 20,060 households. The
HDSS has 16,000 households.

\section{Figure 3: Number of households by source of data}

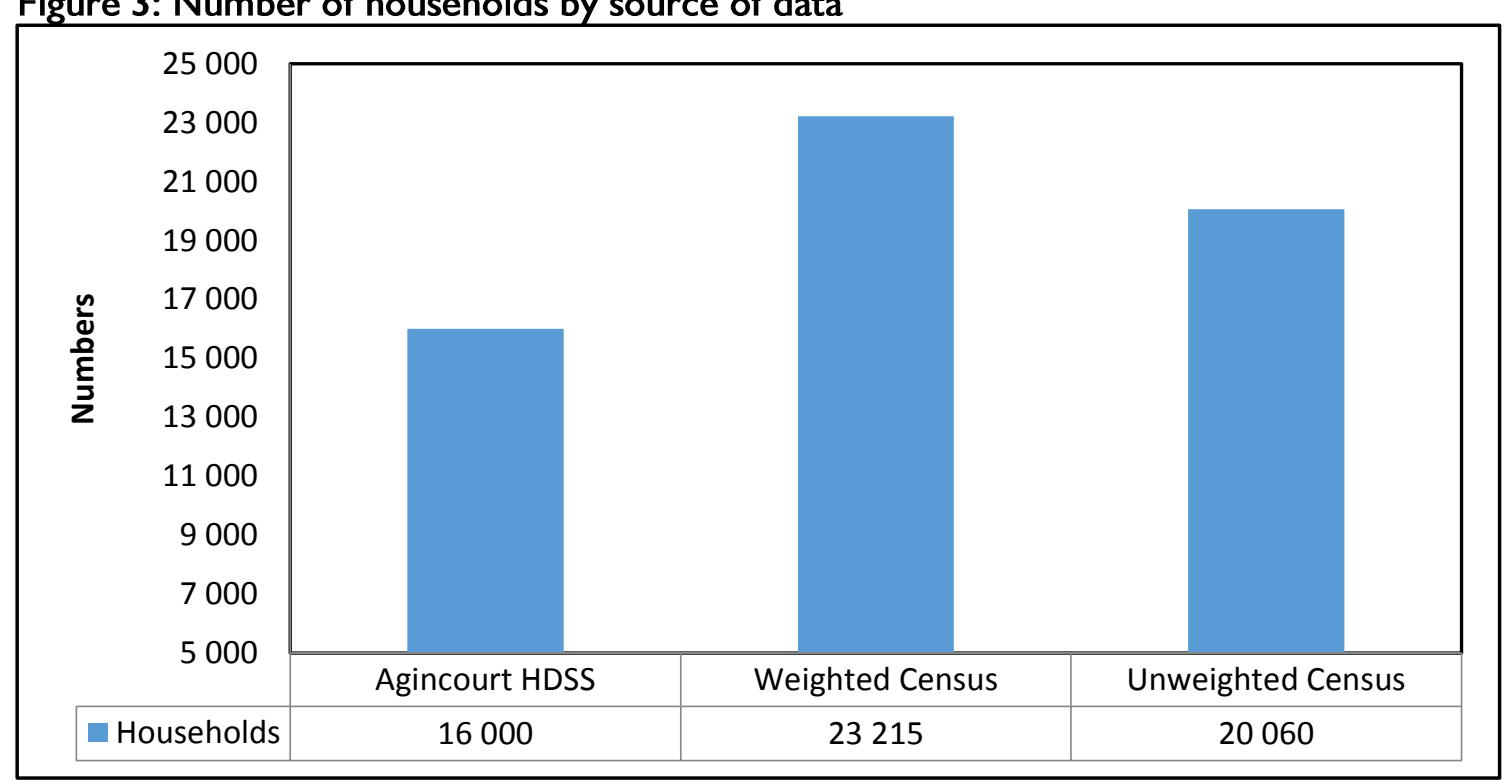

The average household size in this sub-population is 5.58 for the HDSS, which is more than a person larger than in the national census for weighted and unweighted data (Fig. 4). The national census has an average household size of 4.07 for the weighted data and 4.20 for the unweighted data.

\section{Figure 4: Average household size by source of data}

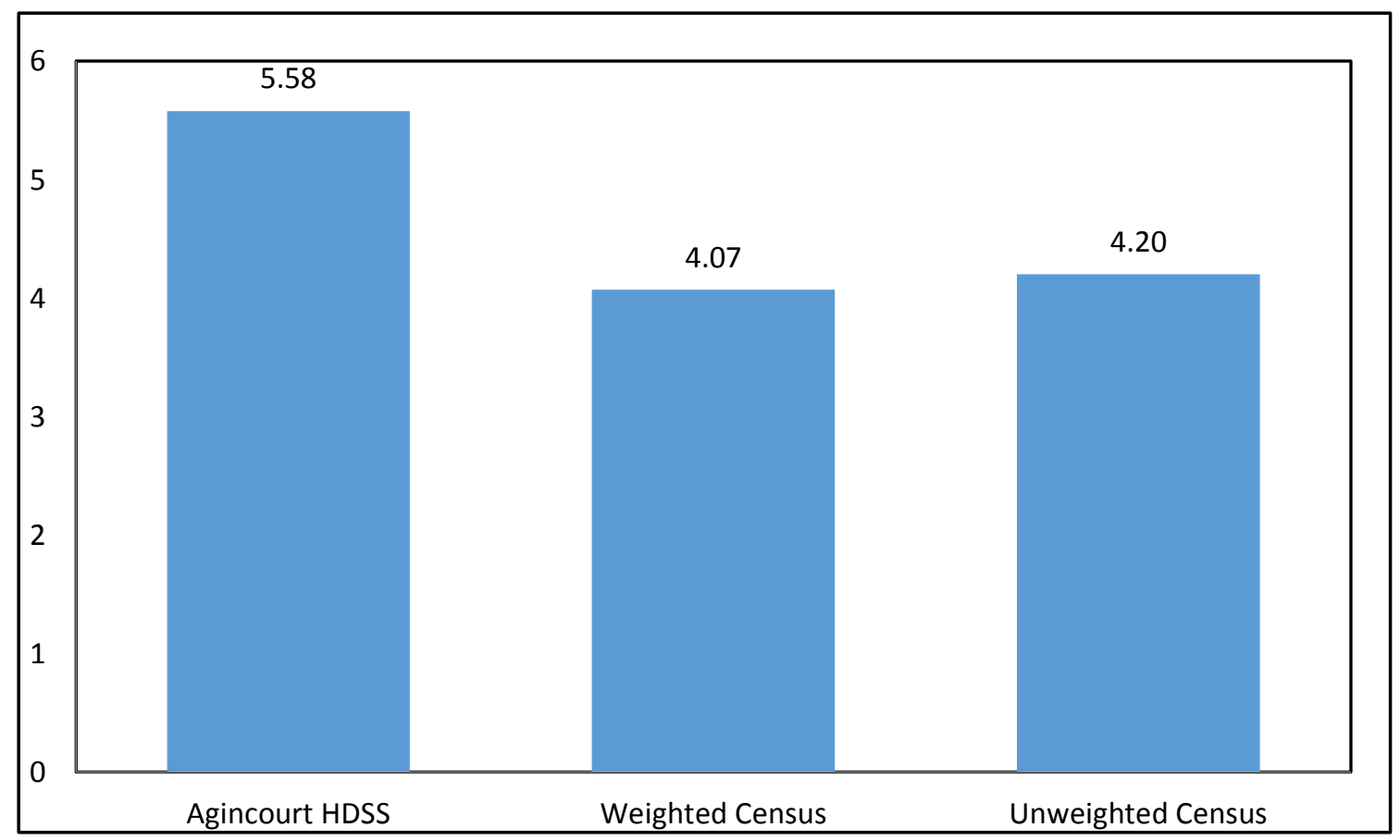

Figure 5 compares the age and sex structure of the population from the two different data sources. For the age-groups 55 years and older, there is a good match of the number of persons in each age-group for both sexes. In the age-group 20-54 years the HDSS has higher counts of working age adult ages, especially for males, but also for females in the 20-34 age group. This is the opposite in the ages $0-19$ years where the difference is in the other direction.

In the $0-19$ age group the national census records more children in the sub-population than HDSS. In each 5-year age-group under age 19 years the HDSS data has slightly fewer children recorded than in the national census. 
Figure 5: Age-sex structure by source of data

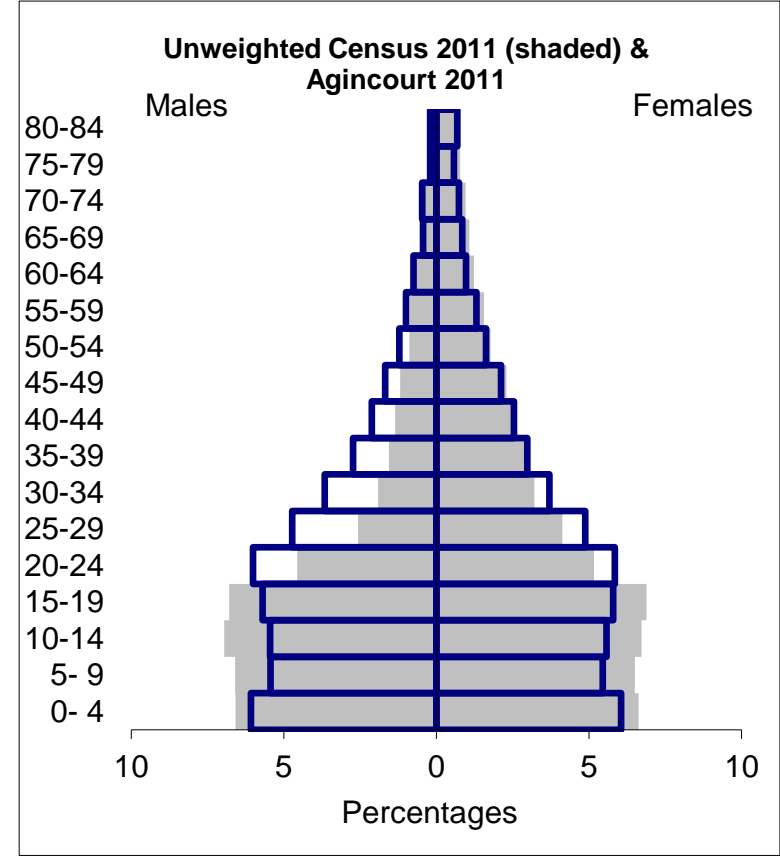

\section{Discussion}

The national census and the HDSS, seek to enumerate the full population, therefore an initial expectation when comparing two census methods for the same population is that the resulting numbers would be similar. The observed differences highlight the fact that for each method the definitions and data collection procedures are somehow reflected in the results.

Important dimensions of difference in national census and HDSS methodology are as follows: in household definitions, the HDSS has a de jure and the national census a de facto definition. In data collection procedures, the HDSS has a longitudinal approach and the national census is cross-sectional. In scale, the HDSS is confined to a sub-district of around 90,000 persons and the national census includes the whole population of around 52 million people. In the HDSS visitors are not included as household members but in census, are included.

The purposes of data collection also vary slightly. The national dataset is a large administrative exercise required by the state to provide insight into population processes, denominators for planning and for policy-making. The HDSS is closer to the concept of a population laboratory, run by health and population scientists, to capture the dynamics in the population, assess mechanisms involved in population change and test specific interventions, and also to inform policy.

The easiest difference to explain in the population numbers described above is that HDSS households are on average larger in size. This is a direct result of the household definition, which deliberately includes

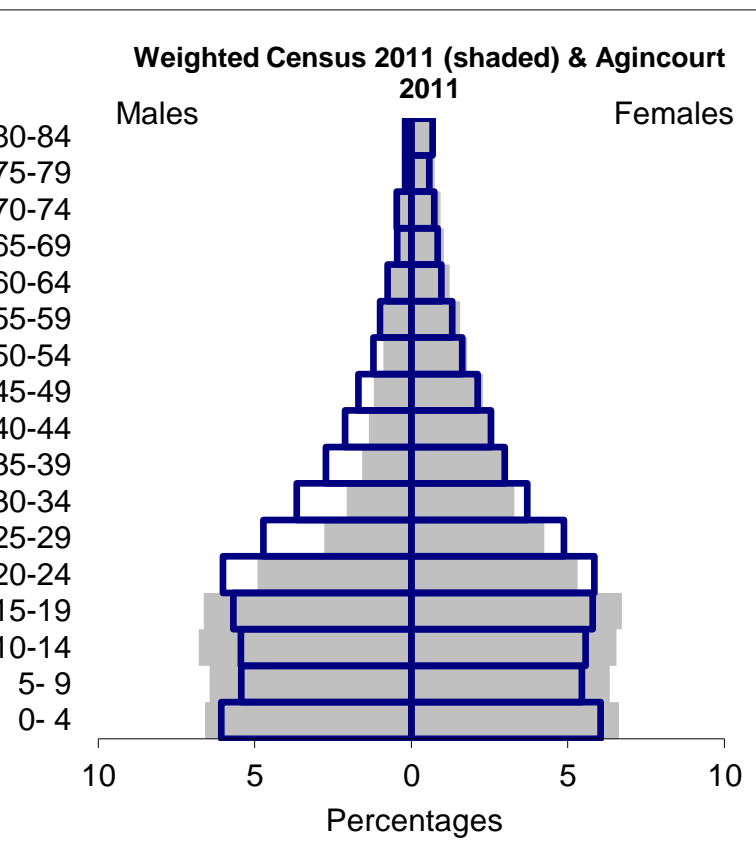

the temporary migrants who belong to the rural household but are temporarily absent for work or education purposes. This innovation in household definition is made possible because households are repeatedly visited and the residence status of members can be verified. It is also made possible by the small geographic scale of data-collection. Doublecounting can be avoided by reconciling migrations within the study site and the fact that most temporary migration that occur is to a destination outside the study site. The proportion of rural household members who are temporary migrants is high, reflecting the structural impact of apartheid labour migration which forced African populations to reside far from employment opportunities and the continued lack of development in the democratic South Africa to absorb the migrants at their place of origin. Rural populations still reside on land that is traditionally owned, which means that poorer households benefit from the low cost of the land and minimal rents. Hence, rural households still tend to be multi-local to access the potential benefits of cities, towns or commercial farms, while retaining a family base in a rural village. And most importantly, Africans maintain strong links with their rural roots and have a special place in their culture.

In the absence of triangulation, it may be difficult to see the extent of temporary labour migration at a population level. Using national census data alone would result in the population counts being biased towards places near work or education, while the vital role of rural (or peri-urban) households can be overlooked in the national socio-economy. 
The comparison of age sex pyramids re-emphasises the presence of high levels of temporary circular migration. The age groups affected by migration are precisely the ones that are larger in the HDSS and smaller in the national census.

The difference in the number of children captured in the national census and HDSS is interesting, and harder to explain. Here we see higher numbers of children on aggregate captured by the national census. This needs exploration to find the source of the difference and again we must look at the way data is collected. It is thought that children of all ages are locally mobile in the rural areas, especially in areas of poverty (Madhavan, et. al., 20I2). Firstly, there is the possibility of a child's parents residing in different locations and the child moving between parental locations and therefore sometimes have multiple household membership. Secondly, there is the practise of fostering, where children relocate to family members that can afford to look after them or who live closer to health services and schools. Within the HDSS, this is handled by a fieldworker determining, which the main place of residence for a child is, i.e. the place where they spend the most time. So the social reality of children's multi-local residence is simplified in order to model children's residence as accurately as possible from an exposure perspective, but not overcomplicate the surveillance operation.

In addition, there may be more local mobility of children than can be captured in the HDSS system. This is reflected in the national census data but with possible double-counting of children as more than one household claims the membership of a multilocal child. This is not following the census rules unless a child stays in two households at the reference period, but slippage of the household definition can be imagined, because people are aware that the census is used to plan public services and unless there is strict probing by the fieldworker a child can be listed in a household even if they are not residing there on the census reference date. The fact of locally mobile children is complex to manage in either system. As with the case of labour migration, it can be a direct consequence of the socially disruptive historical context and the subsequent spatial inequities that still plague the country. The fabric of home and work remain tenuous, especially in the poorest households and children are mobile as a result. The challenge of reflecting this in census data is shown by the triangulation used in this paper. The Africa Centre HDSS in northern KwaZulu-Natal considers multiple household memberships (Muhwava, et. al., 2007).

The difference in population numbers in the same geographic area reflected in the two systems is largely a consequence of the different household definitions. The HDSS should show a larger population, as it does in comparison with the unweighted data. On aggregate this is slightly off-set by the census picking up more children without which the difference would be even greater. The weighting of the national census data recovers the difference and shows that the weighted number of the de facto population is closer to the de jure population shown in the HDSS.

The larger number of households recorded in the national census compared to the HDSS is a harder result to explain. There can be structural features contributing to this difference. In a recent community meeting in Agincourt, a village elder said that when using a household definition of eating from the same pot, this puts people together that otherwise live apart (Rhian Twine - personal communication). In other words, the census is picking up more households than the HDSS because households that live in separate dwellings while sharing resources probably report themselves as separate households during the census. On the other hand the difference can possibly be attributed to errors in data collection. More work is needed to explore whether this can account for the gap between the numbers of household reported in the national census and the HDSS.

From the research, the contribution of circular migration to the household composition is evident. Research has highlighted the contribution of the return migrants to the burden of disease (Bocquier et al., 2014; Clark et al., 2007). Policy should take into account the life cycle of migrants. Policy should also cater for the different populations in the sending and receiving areas. What has also emerged is that the household definition used explains the differences seen in the study, and for planning purposes different data sources should be used to complement each other.

\section{Conclusion}

It should not be surprising that different household definitions result in different household and population counts. It can be instructive to use these differences to learn some of the complex dynamics that exist in South Africa's rural areas, particularly due to high levels of migration and local mobility. These can be explored further by comparing the national census with Agincourt HDSS data in different years, as well as repeating the exercise with other HDSS centres in other parts of the country, namely the Africa Centre HDSS in KwaZulu-Natal and the Dikgale HDSS in Limpopo. 
A systematic process of triangulation and interrogation of census results can provide insight into household dynamics, especially in highly mobile populations. Observed differences can have implications for the training of census fieldworkers and for the interpretation of analytic results. However, triangulation is problematic due to lack of a gold standard with which to compare results obtained from the multiple sources of data used.

\section{Acknowledgements}

The authors of this paper are indebted to Statistics South Africa and the MRC/Wits Rural Public Health and Health Transitions Research Unit for access to data, and to Statistics South Africa Geography and stakeholder relations for helping with data preparations. The Agincourt Health and Demographic Surveillance System (HDSS) is supported by the South African Medical Research Council, University of the Witwatersrand and National Research Foundation; and by the Wellcome Trust, UK (grants 058893/Z/99/A; 069683/Z/02/Z; 085477/Z/08/Z; 085477/B/08/Z). The communities of the Agincourt sub-district are actively engaged contributors to the health and demographic surveillance system, as are district and provincial managers in health, education and other government sectors in Mpumalanga Province.

\section{References}

Bennett, R., Hosegood, V., Newell,M., McGrath,N. 2015. "Understanding family migration in rural South Africa: Exploring children's inclusion in the destination households of migrant parents." Population, Space and Place, 21: 310-321.

Byass, P., Kahn, K., Fottrell, E., Collinson, M.A. and Tollman, S.M. 2010. "Moving from data on deaths to public health policy in Agincourt, South Africa: approaches to analysing and understanding verbal autopsy findings." PLoS Med, 7(8).

Clark, S. J., Collinson, M. A., Kahn, K., Drullinger, K., and Tollman, S. M. 2007. "Returning home to die: Circular labour migration and mortality in South Africa". Scandinavian Journal of Public Health. Supplement, 69: 35-44.

Collinson, M.A. 2010. "Striving Against Adversity: The Dynamics of migration, health and poverty in rural South Africa." Global Health Action, 3.

Dolan, C., Tollman, S., Nkuna, V and Gear, J. 1997. "The Links between legal status and environmental health: A case study of Mozambican refugees and their hosts in the Mpumalanga (Eastern Transvaal) Lowveld, South Africa." International Journal of Health and Human Rights, 2(2): 62-84.
Ginsburg, C., Collinson, M.A., Gómez-Olivé, F.X., Kahn, K., Tollman, S.M. "Migration and settlement change in South Africa: Triangulating census 20I I with longitudinal data from the Agincourt Health and Demographic Surveillance System." Southern African Journal of Demography (In press).

Kabudula, C.W., Joubert, J.D., Tuoane-Nkhasi, M., Kahn, K., Rao, C., Gmez-Oliv, F.X., Mee, P., Tollman, S., Lopez, A.D., Vos, T. and Bradshaw, D. 20I4. "Evaluation of record linkage of mortality data between a health and demographic surveillance system and national civil registration system in South Africa." Population Health Metrics, I2(I).

Kahn, K., Collinson, M.A., Gómez-Olivé, F.X., Mokoena, O., Twine, R., Mee, P., Afolabi, S.A., Clark, B.D., Kabudula, C.W., Khosa, A., Khoza, S., Shabangu, M.G., Silaule, B., Tibane, J.B., Wagner, R.G., Garenne, M.L., Clark S.J and Tollman, S.M. 2012. "Profile: Agincourt Health and Sociodemographic Surveillance System." International Journal of Epidemiology, 4I (4): 988-I00I.

Kiregyera, B. 2015. The Emerging Data Revolution in Africa: Strengthening the Statistics, Policy and Decision-making Chain. Stellenbosch. AFRICAN SUN MeDIA.

Leibbrandt, M., Woolard, I. and de Villiers, L. 2009. Methodology: Report on NIDS wave I. Technical paper, I. National Income Dynamics Study, University of Cape Town

Madhavan, S., Schatz E. and Clark, B. 2009. "Effect of HIV/AIDS-related mortality on household dependency ratios in rural South Africa, 20002005." Population Studies, 63(I): 37-5I.

Madhavan, S., Schatz, E., Clark, S.J. and Collinson, M.A. 2012. "Child mobility, maternal status and household composition in rural South Africa." Demography, 49(2): 699-718.

McDaniel, A and Zulu, E. 1996. "Mothers, Fathers, and Children: Regional Patterns in Child-Parent Residence in Sub-Saharan Africa." African Population Studies, II.

Mostert, W.P., J.L. van Tonder and B.E. Hofmeyr. 1987. Rekonstruksie van die Sensusouderdomstrukture van die Suid-Afrikaanse Swart Bevolking: 1936 tot 1985 [Reconstruction of the Census Age Structure of the South African Black Population: 1936 to 1985]. Report S153(1987). Pretoria: Human Sciences Research Council.

Moultrie, T and Timaeus, I. 2002. Trends in South African Fertility between 1970 and 1998: An Analysis of the 1996 Census and the 1998 Demographic and Health Survey Technical Report. Cape Town, Burden of Disease Research Unit: Medical Research Council. 
Muhwava, W, Nyirenda, M, Mutevedzi, T, Herbst, K, \& Hosegood, V. (2007). Operational and methodological procedures of the Africa Centre Demographic Information System Monograph Series no. I. Africa Centre for Health and Population Studies, South Africa.

Posel, D. and Casale, D. 2003. "What has been happening to internal labour migration in South Africa, 1993-1999?" South African Journal of Economics, 7 I (3): 455-479.

Rabe, M., 2008. "Can the 'African household' be presented meaningfully in large-scale surveys?" African Sociological Review/Revue Africaine de Sociologie:|67-18|.

Republic of South Africa. (201 I). National Development Plan 2030: Our Future-Make it Work.

Republic of South Africa. (1998). Population Policy for South Africa. Department of Social Development.

Russell, M. 2003. "Are urban black families nuclear? A comparative study of black and white South African family norms." Social Dynamics, 29(2): I53-I76.

Statistics South Africa (20I2). Census 20I I Metadata. Pretoria: South Africa.

Statistics South Africa (2014). General Household Survey, Statistical Release P03 18

\footnotetext{
ESRI: (Environmental Systems Research Institute) is an international supplier of Geographic Information System (GIS) software, web GIS and geodatabase management applications.
}

Tollman, S. (1999). "The Agincourt field site Evolution and current status." South African Journal of Medicine, (89): 855-857.

United Nations. (1954). Handbook of Population Census Methods. New York, NY:Statistical Office of the United Nations,Department of Economic Affairs.

Van de Walle, E. 2006. African households: censuses and surveys. ME Sharpe.

Wittenberg, M. and Collinson M.A. 2008. Restructuring of households in rural South Africa: Reflections on average household size in the Agincourt sub-district, 1992-2003. Working Paper Number 12. Cape Town: SALDRU, University of Cape Town.

Wittenberg, M., Collinson M.A and Harris T, "Decomposing changes in household measures: Household size and services in South Africa 199420I2", Manuscript submitted for publication.

Young, L \& Ansell, N. 2003. "Fluid households, complex families: The impacts of children's migration as a response to HIV/AIDS in Southern Africa." The Professional Geographer, 55(4): 464476.

Ziehl, S.C. 200I. "Documenting changing family patterns in South Africa: A census data of any value." African Sociological Review/Revue Africaine de Sociologie, 5(2):36-62. 